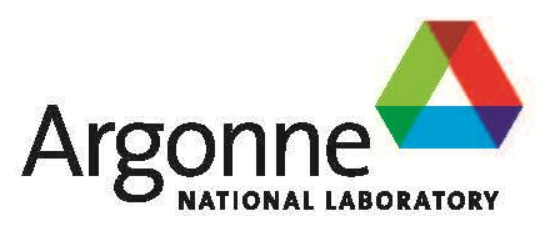

\title{
Anodic Dissolution of Uranium under Slightly Alkaline Conditions
}

Progress Report-Full-Scale Demonstration with Irradiated LEU Foil

Chemical Sciences and Engineering Division 


\begin{abstract}
About Argonne National Laboratory
Argonne is a U.S. Department of Energy laboratory managed by UChicago Argonne, LLC under contract DE-AC02-06CH11357. The Laboratory's main facility is outside Chicago, at 9700 South Cass Avenue, Argonne, Illinois 60439. For information about Argonne and its pioneering science and technology programs, see www.anl.gov.
\end{abstract}

\title{
DOCUMENT AVAILABILITY
}

Online Access: U.S. Department of Energy (DOE) reports produced after 1991 and a growing number of pre-1991 documents are available free via DOE's SciTech Connect (http://www.osti.gov/scitech/)

Reports not in digital format may be purchased by the public from the National Technical Information Service (NTIS):

U.S. Department of Commerce

National Technical Information Service

5301 Shawnee Rd

Alexandra, VA 22312

unw.ntis.gov

Phone: (800) 553-NTIS (6847) or (703) 605-6000

Fax: (703) 605-6900

Email: orders@ntis.gov

Reports not in digital format are available to DOE and DOE contractors from the Office of Scientific and Technical Information (OST):

U.S. Department of Energy

Office of Scientific and Technical Information

P.O. Box 62

Oak Ridge, TN 37831-0062

unw.osti.gov

Phone: (865) 576-8401

Fax: (865) 576-5728

Email: reports@osti.gov

\section{Disclaimer}

This report was prepared as an account of work sponsored by an agency of the United States Government. Neither the United States Government nor any agency thereof, nor UChicago Argonne, LLC, nor any of their employees or officers, makes any warranty, express or implied, or assumes any legal liability or responsibility for the accuracy, completeness, or usefulness of any information, apparatus, product, or process disclosed, or represents that its use would not infringe privately owned rights. Reference herein to any specific commercial product, process, or service by trade name, trademark, manufacturer, or otherwise, does not necessarily constitute or imply its endorsement, recommendation, or favoring by the United States Government or any agency thereof. The views and opinions of document authors expressed herein do not necessarily state or reflect those of the United States Government or any agency thereof, Argonne National Laboratory, or UChicago Argonne, LLC. 


\section{Anodic Dissolution of Uranium under Slightly Alkaline Conditions}

Progress Report-Full-Scale Demonstration with Irradiated LEU Foil

by

M. Alex Brown, Artem V. Gelis, Stan Wiedmeyer, and George F. Vandegrift

Chemical Sciences and Engineering Division, Argonne National Laboratory

prepared for

U.S. Department of Energy, National Nuclear Security Administration,

Office of Defense Nuclear Nonproliferation

July 2014 



\section{CONTENTS}

ABSTRACT

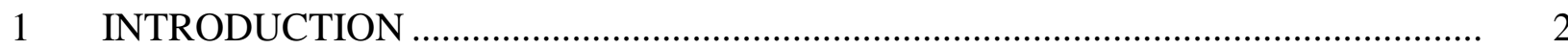

2 DISSOLVER TANK: DESIGN AND ELECTROLYSIS EXPERIMENTS ................ 4

$3 \quad$ PRECIPITATION AND FILTRATION ....................................................... 7

4 LOW-BURNUP EXPERIMENT WITH LEU FOIL ............................................ 9

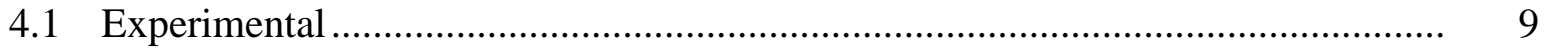

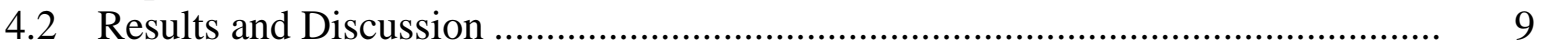

5 CONCLUSION AND FUTURE ACTIVITIES .................................................. 12

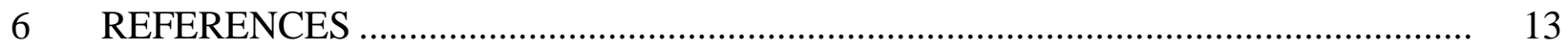

\section{FIGURES}

$1 \quad$ Flow Diagram of Mo-99 Front-End Processing of LEU Foils Using Electrodissolution and Precipitation ............................................................... 3

2 Illustration of the Dissolver Tank and Electrochemical Basket............................... 4

3 Photograph of the Dissolver and the Anode Basket ......................................... 5

$4 \quad$ Illustration of the Mixing Vessel ..............................................................

$5 \quad$ Full Process Setup Used for the Low-Burnup LEU Experiment Inside a

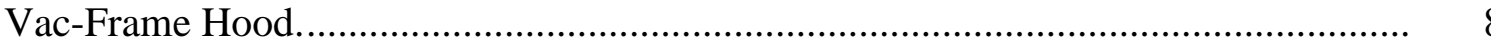

6 Photograph of Samples Taken from the Dissolver Solution, Uranium Precipitate, $\mathrm{NaOH}$ Aluminum Solution, and the Product Solution

\section{TABLE}

1 Gamma analysis Results of the Electrochemical Dissolver Process 
This page intentionally left blank 


\title{
ANODIC DISSOLUTION OF URANIUM UNDER SLIGHTLY ALKALINE CONDITIONS \\ PROGRESS REPORT-FULL-SCALE DEMONSTRATION WITH IRRADIATED LEU FOIL
}

\begin{abstract}
Argonne National Laboratory is developing an alternative method for digesting irradiated foil targets of low enriched uranium to produce Mo-99 in neutral/alkaline media. This method consists of the electrolytic dissolution of irradiated uranium foil in sodium bicarbonate solution, followed by precipitation of base-insoluble fission products, activation products, and actinide-carbonate species with calcium oxide. Molybdenum, technetium, and iodine remain in solution. The electrochemical dissolver and mixing vessel were designed and fabricated with Type 304 stainless steel and tested for the processing of a full-size irradiated uranium foil. The resulting product solution can be directly fed into existing commercial Mo-purification processes.
\end{abstract}




\section{INTRODUCTION}

In light of the Global Threat Reduction Initiative (GTRI), which addresses nuclearproliferation issues, the production of the medical isotope Tc- $99 \mathrm{~m}$ and its parent isotope Mo-99 should not rely on the use of high enriched uranium (HEU). However, to produce HEUequivalent amounts of Mo-99 with low enriched uranium (LEU), an approximate five-fold increase of uranium is needed to match the thermal neutron fission yields [Vandegrift et al., $2002 \mathrm{~b}]$. Consequently, increasing the amount of uranium by five times and changing the form of uranium in a target will have a profound effect on the current chemical processing of the irradiated targets, and new chemical treatments must be devised.

Caustic digestion of irradiated aluminum- HEU targets is already employed for Mo-99 production [Vandegrift et al., 2002a]. However, under normal conditions, uranium metal is only slowly digested in $\mathrm{NaOH}$. With the aid of $\mathrm{H}_{2} \mathrm{O}_{2}$, digestion can be accelerated, but is cumbersome and difficult to control [Vandegrift et al., 2002a]. High temperatures are needed for the digestion with sodium hydroxide, which necessitates the use of a high-pressure vessel to reach a temperature of $\sim 275^{\circ} \mathrm{C}$ [Gelis et al., 2003]. Without oxidizing agents, uranium metal can be oxidized in basic solutions using a potential difference of about $2 \mathrm{~V}$. Supplying over-potential and slightly elevated temperatures can accelerate this digestion.

Using alkali solutions for short-cooled irradiated LEU processing has several advantages over the more common acidic nitrate approach. The digestion of uranium metal in nitric acid produces substantial amounts of undesirable $\mathrm{NO}_{x}$ gases, which demand some degree of off-gas treatment. The chemical speciation of iodine - a major fission product - exists as predominantly $\mathrm{I}_{2}$ under acidic conditions [Gottardi, 2000]. In its elemental form, iodine is volatile and creates challenges for containing radioiodine in the processing plant. In alkali solutions, iodine is in the reduced anionic forms $\mathrm{I}^{-}$or $\mathrm{I}_{3}{ }_{3}$, which are not volatile. The remainder of the fission products such as zirconium, lanthanides, barium, and cesium can be co-precipitated with uranium and calcium carbonate in basic solution.

In this effort, we have tested a relatively low-temperature, ambient-pressure procedure employing anodic oxidation of the irradiated uranium metal into basic bicarbonate media. The separation of Mo-99 was carried out by the precipitation of fission products, uranium, and carbonate from the solution with calcium oxide. The process schematic is shown in Figure 1. The goal of this study was to verify the feasibility of this technology and to identify key optimizing factors for the development of an industrial-scale procedure. 


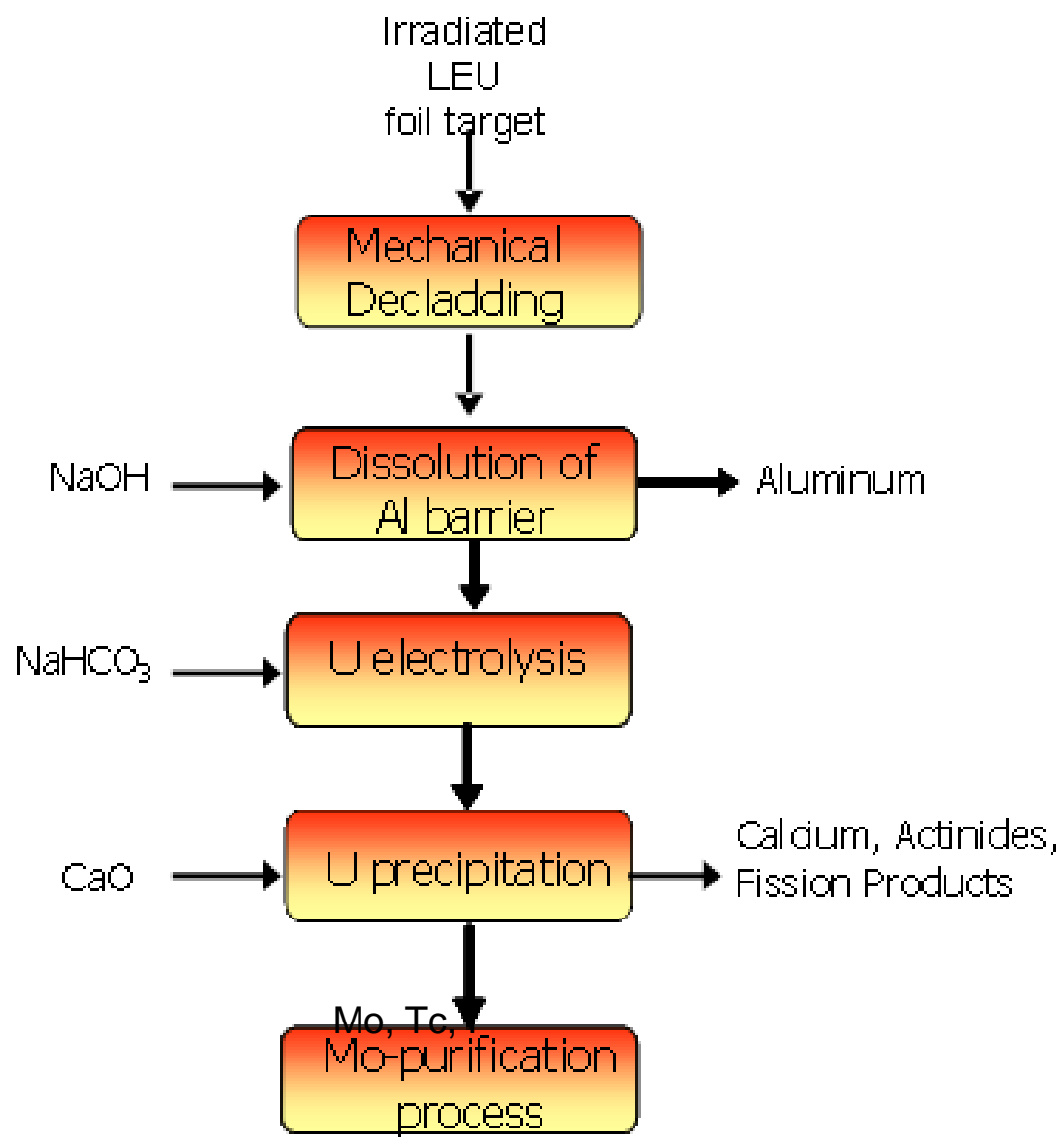

FIGURE 1 Flow Diagram of Mo-99 Front-End Processing of LEU Foils Using Electrodissolution and Precipitation 


\section{DISSOLVER TANK: DESIGN AND ELECTROLYSIS EXPERIMENTS}

The oxidation of uranium metal is assumed to proceed quickly through U(III), producing $\mathrm{U}(\mathrm{IV})$ oxide. Then, according to literature data, the oxidation of $\mathrm{UO}_{2}$ proceeds through the formation of $\mathrm{UO}_{2+\mathrm{x}}$ species on the surface until $\mathrm{UO}_{3} \cdot 2 \mathrm{H}_{2} \mathrm{O}$ is formed [Sunder et al., 1996]. Hexavalent uranium has rather high solubility in the presence of carbonate/bicarbonate ions [McLaren et al., 1950]. The dissolution occurs when these negative ions reach the positively charged surface of the uranium anode.

A schematic of the basket and the dissolver is shown in Figure 2, and Figure 3 is a photograph of the dissolver and the anionic basket. The basket's vertical bolt pushes the outer frame with the welded screen toward the inner frame with the attached screen, thus providing the necessary contact between the anode lead and the foil. We have found that, using this basket, it takes about $2.5 \mathrm{~h}$ to dissolve nearly $99 \%$ of a full-size foil. The relatively high rate of the dissolution is due to the partial reduction of the free foil surface area, caused by the compact mesh interference.

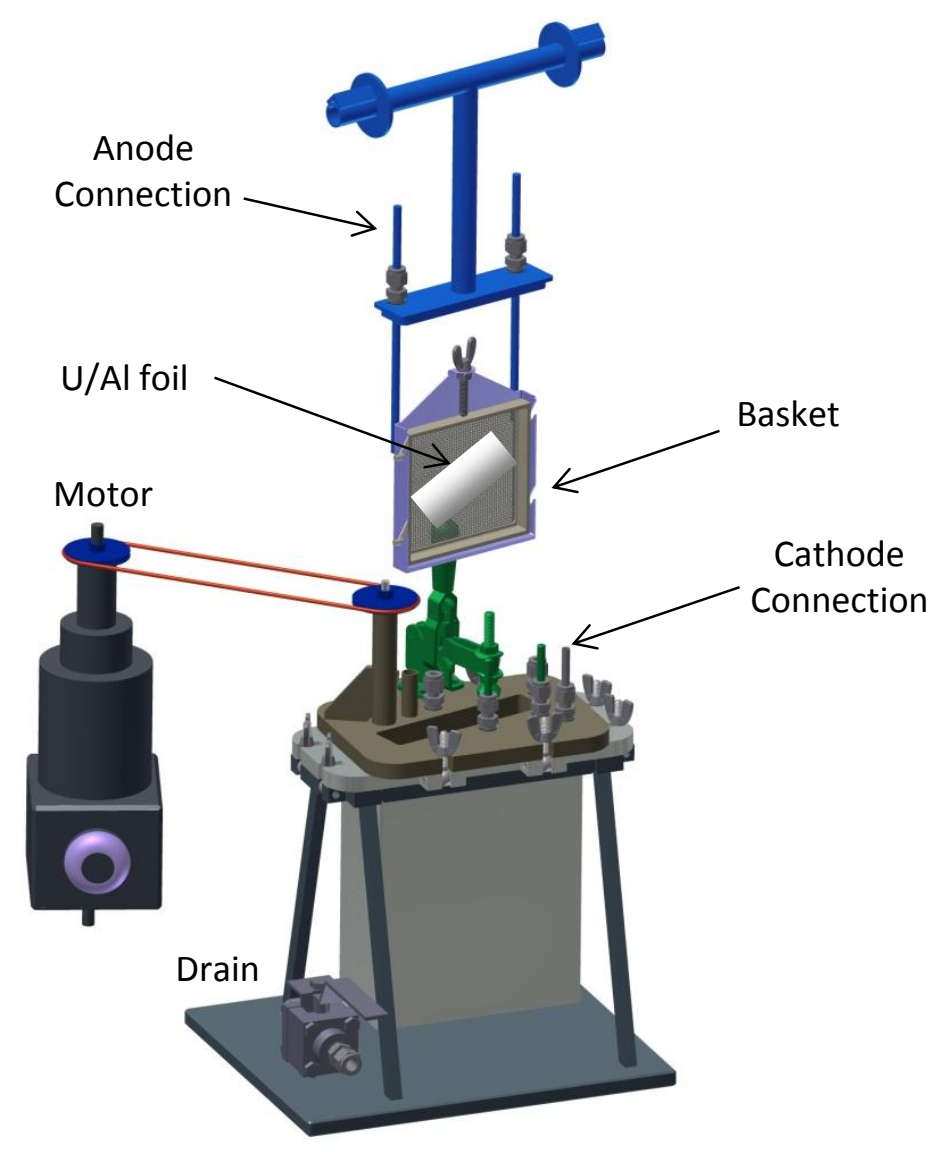

FIGURE 2 Illustration of the Dissolver Tank and Electrochemical Basket 


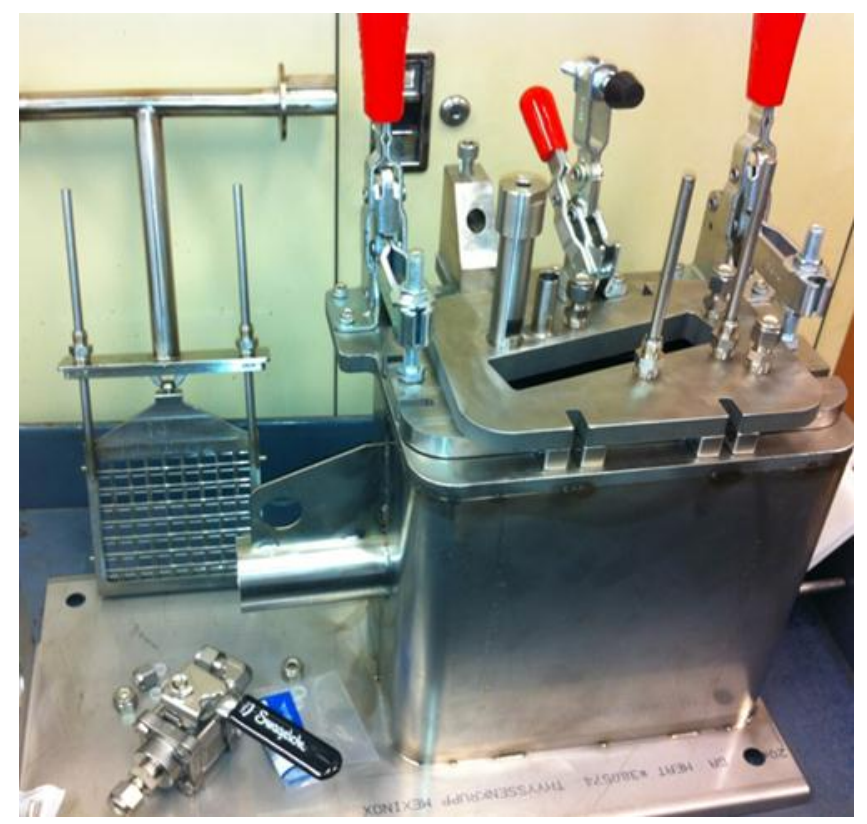

FIGURE 3 Photograph of the Dissolver and the Anode Basket

The material used for the prototype is Type 304 stainless steel (SS). Nitrogen gas is used to sweep the dissolver. In actual process application, fission gases will be collected and hydrogen gas, which is generated during the electrolysis, will need to be oxidized for commercial-scale processing, but both were diluted and released in this experiment.

The first step in the process is the dissolution of an $\mathrm{Al}$ barrier in $1 \mathrm{M} \mathrm{NaOH}$ as $\mathrm{NaAl}(\mathrm{OH})_{4}$. Then, the solution is drained through a ball valve on the side of the dissolver (Figures 2 and 3). After a wash step, a sodium bicarbonate solution is added to the dissolver through one of the ports on the lid. The uranium foil electrolysis is conducted by means of intense stirring at elevated temperature $\left(85-95^{\circ} \mathrm{C}\right)$. Heating is provided by an external heat gun (not shown).

The volume of the solution required to cover a $24 \mathrm{~g}$ uranium foil $(10 \mathrm{~cm} \times 8 \mathrm{~cm})$ is about 1.2 L. However, the solution/U-metal ratio will be significantly smaller if a batch of several foils is dissolved in a vessel modified for the full-scale process. The solubility of uranium in bicarbonate medium is $80 \mathrm{~g}-\mathrm{U} / \mathrm{L}$ (it is soluble as both the neutral and anionic complexes of uranyl carbonate) [McLaren et al., 1950]; thus, a $225 \mathrm{~g}$ batch of $\mathrm{U}$ foils requires at least $3 \mathrm{~L}$ of the solution. For the full-size dissolver, the anode basket(s) will be fabricated from nickel or nickel alloys, which are resistant to oxidation in alkaline mediums. Use of 304 SS is acceptable for the prototype demonstration, so it was chosen to minimize the cost. The cathode and the dissolver body of the production dissolver can be made from stainless steel, as there should be no significant corrosion during the process. 
Our preliminary tests showed that 20-22 g depleted uranium (DU) foils are completely dissolved in $1 \mathrm{M} \mathrm{NaHCO}_{3}$ at $90^{\circ} \mathrm{C}$ within approximately $1.5 \mathrm{~h}$. The foils were connected to the anode lead via a clip, hanging freely in the solution, while the solution was intensively stirred. However, to avoid the risk of dropping the foil into the dissolver, an anode basket or a cage should be used.

The following dissolution tests were conducted using a direct-current (DC) power supply by Magna Power with a voltage range of 0-32 V and a current range of 0-62 A. The foil was placed in the anode basket between two SS coarse screens, which were tightened together. A $23.7 \mathrm{~g}$ piece of DU foil, $0.125-\mathrm{mm}$ thick $(10 \mathrm{~cm} \times 7.5 \mathrm{~cm})$, was wrapped in $0.1-\mathrm{mm}$ thick Al foil $(4.5 \mathrm{~g})$ and was placed in the anode basket. To dissolve the $\mathrm{Al}$ recoil barrier, $1.2 \mathrm{~L}$ of $1.1 \mathrm{M}$ $\mathrm{NaOH}$ was added to the dissolver. The solution was intensely stirred and heated to $60^{\circ} \mathrm{C}$ using a heat gun. The temperature was maintained for $5 \mathrm{~min}$., then heating was stopped, and the resultant solution was drained by gravity. The basket was removed from the dissolver to ensure the completeness of $\mathrm{Al}$ dissolution. No $\mathrm{Al}$ foil remained in the basket. A small amount of black solids, presumably hydrous $\mathrm{UO}_{2}$, was found in the solution. The $\mathrm{UO}_{2}$ was likely removed from the DU foil surface due to the agitation. No significant $\mathrm{UO}_{2}$ formation is expected in alkaline medium under the experimental conditions.

To dissolve the uranium foil, we added 1.2 $\mathrm{L}$ of $1 \mathrm{M} \mathrm{NaHCO}_{3}$ to the dissolver after rinsing the vessel with $100 \mathrm{~mL} \mathrm{H}_{2} \mathrm{O}$. The solution was heated to $85^{\circ} \mathrm{C}$, and the electrolysis was started. Nitrogen gas was continuously used for sweeping the dissolver head space. The temperature was maintained at $90 \pm 5^{\circ} \mathrm{C}$. For the first hour, the current was maintained at $29 \mathrm{~A}$, while the voltage was in the 6.0-6.3 $\mathrm{V}$ range. After $1 \mathrm{~h}$, the process was stopped, and the foil was removed from the basket, washed with water, dried, and weighed on the scale. Exactly $10 \mathrm{~g}$ had been dissolved. Because the dissolution rate was considered to be unsatisfactory, for the remaining time the experiment was conducted at $\approx 8.5 \mathrm{~V}$ and $40-45 \mathrm{~A}$. After $1.5 \mathrm{~h}$ from the restart $(2.5 \mathrm{~h}$ total), the electrolysis was terminated. After inspection, only a small piece $(0.78 \mathrm{~g})$ of DU was left. Therefore, about $97 \%$ of the foil had been dissolved in $2.5 \mathrm{~h}$, although the rate can be further improved by applying a higher potential. 


\section{PRECIPITATION AND FILTRATION}

The precipitation step shown in Figure 1 is the critical step to remove actinides and the majority of the fission products from the product solution. The mixing vessel was built with $304 \mathrm{SS}$ and designed to hold $2 \mathrm{~L}$ of solution (Figure 4).

The base of the vessel was built with an incline to assist the flow of the uranium carbonate slurry and to avoid clogging. Five ports were drilled into the head of the vessel: a funnel to introduce the calcium oxide powder, a mixing port to hold the stir-shaft, and three connections for the vacuum, solution entrance, and $\mathrm{N}_{2}$ gas. The exit valve diameter was $1 / 2-\mathrm{in}$. to allow the slurry to move freely to the filter. An in-line $10-\mu \mathrm{m}$ Whatman filter with $1 / 2$-in. barbed connections was used to capture the slurry. Figure 5 is a photograph of the entire apparatus in a vac-frame hood.

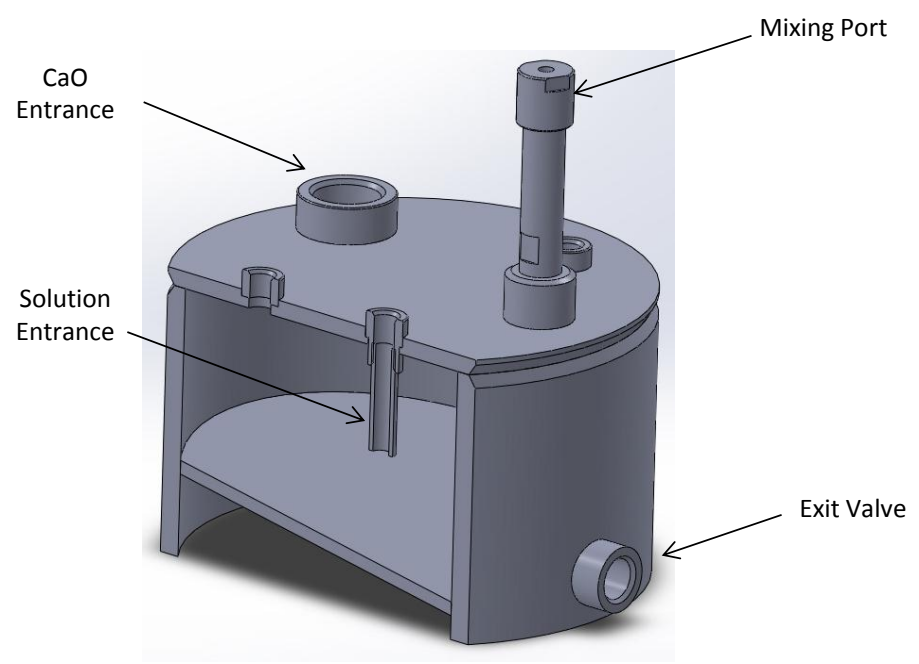

FIGURE 4 Illustration of the Mixing Vessel 


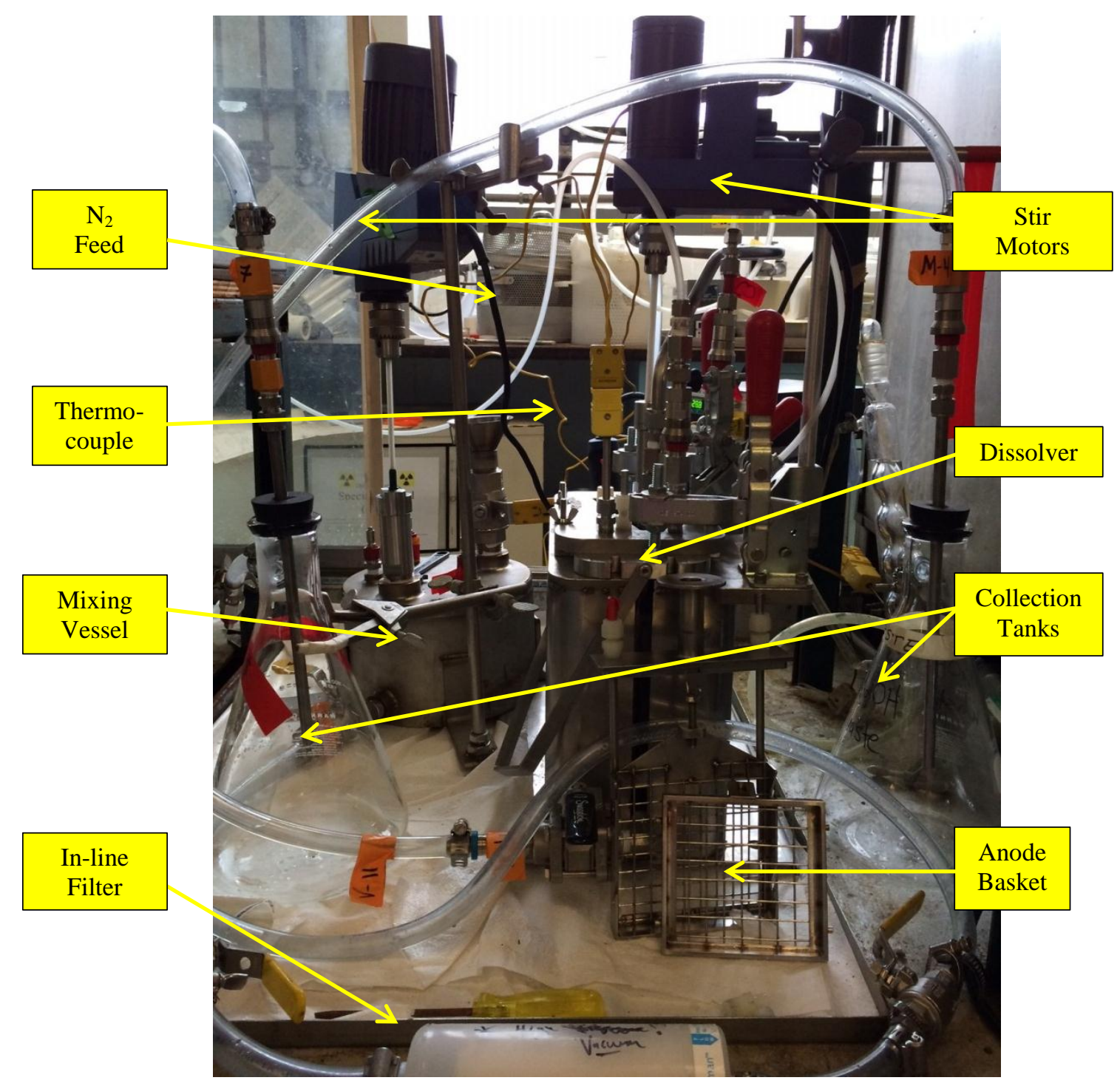

FIGURE 5 Full Process Setup Used for the Low-Burnup LEU Experiment Inside a Vac-Frame Hood 


\section{LOW-BURNUP EXPERIMENT WITH LEU FOIL}

\subsection{EXPERIMENTAL}

A $7.6 \mathrm{~cm} \times 2.5 \mathrm{~cm}$ LEU foil $(0.2-\mathrm{mm}$ thick, 15.3 -g mass) was obtained from laboratory stock. The foil was wrapped in aluminum and placed into an irradiation vessel that had been purged with helium. The vessel was then irradiated for $10 \mathrm{~min}$ at the Argonne low energy accelerator facility (LINAC) using a neutron converter; the thermal neutron flux was on the order of $10^{11} \mathrm{n} \cdot \mathrm{cm}^{-2} \cdot \mathrm{s}^{-1}$. The target was allowed to cool for eight hours to minimize the dose rate from short-lived fission products.

The target was removed from the irradiation vessel, secured in the dissolver basket, and placed into the dissolver. The basket was then submerged in $1.5 \mathrm{~L}$ of $1 \mathrm{M} \mathrm{NaOH}$ under a continuous $\mathrm{N}_{2}$ sweep with intense mixing at $70^{\circ} \mathrm{C}$. It took approximately $45 \mathrm{~min}$ to completely dissolve the aluminum and leave the uranium metal exposed and in contact with the basket. The $\mathrm{NaOH}$ solution was drained from the dissolver into a collection flask for analysis, and the dissolver was filled with $1.2 \mathrm{~L}$ of $0.9 \mathrm{M} \mathrm{NaHCO}_{3}$. Anode and cathode leads were connected to the basket and dissolver, respectively. Using the Magna Power supply described earlier, we maintained the current at $41 \pm 2 \mathrm{~A}$ and voltage at $9 \mathrm{~V}$, with continuous mixing. The temperature of the solution was $92 \pm 2{ }^{\circ} \mathrm{C}$. Nitrogen gas was continuously flushed through the dissolver and into a condensing coil and liquid trap. After four hours, the electrolysis was stopped, and the foil was examined. Over $98 \%$ of the uranium foil was dissolved in approximately $650 \mathrm{~mL}$ of carbonate solution ( $\mathrm{pH} \mathrm{10.0).} \mathrm{An} \mathrm{aliquot} \mathrm{of} \mathrm{the} \mathrm{solution} \mathrm{was} \mathrm{taken} \mathrm{for} \mathrm{analysis.} \mathrm{The} \mathrm{solution} \mathrm{was}$ then fed into the mixing vessel, where it was contacted with $89 \mathrm{~g}$ of calcium oxide. The solution was mixed for approximately $15 \mathrm{~min}$ and rinsed with deionized water to flush precipitates from the mixing vessel. The slurry then exited the vessel through the in-line Whatman filter and was weighed in a collection flask (1.16 L total, $\mathrm{pH} 13.0)$. The product solution was visibly clear, indicating that most of the uranium had been removed. An aliquot of the product solution was taken for analysis. The uranium precipitate that was captured on the filter was eluted with concentrated nitric acid. A small volume of acidic $0.5 \mathrm{M}$ stable Mo carrier was added to the eluted solution with $2 \%$ alpha-benzoin-oxime $(\alpha B O)$ [Wu et al., 1994]. The precipitate was filtered, dried, and then digested in sodium hydroxide and hydrogen peroxide to a final volume of 0.215 L. An aliquot of this solution (labelled "Mo Separated Filter" in Table 1) was taken for analysis. Samples of these solutions are shown in Figure 6.

\subsection{RESULTS AND DISCUSSION}

The samples were gamma-counted on a high-purity germanium well-detector (calibrated with an Eckert \& Ziegler mixed isotope standard). The activities of each nuclide were decaycorrected to the time of irradiation. The dead time in each case was less than 5\%. The Mo-99 concentrations were determined from the gamma peak at $778 \mathrm{keV}$. Table 1 lists the results of the analysis. 


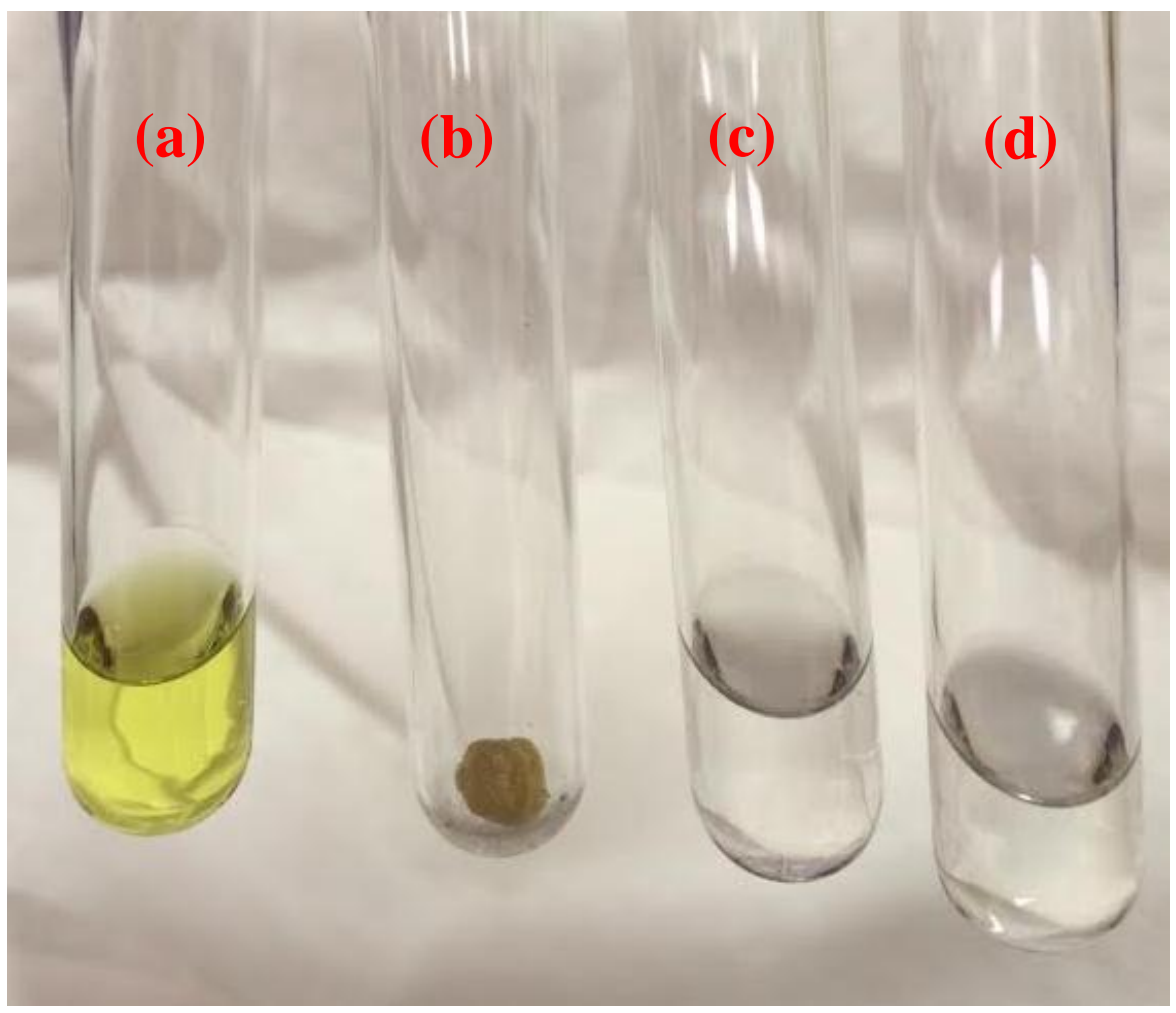

FIGURE 6 Photograph of Samples Taken from (a) the Dissolver Solution, (b) Uranium Precipitate, (c) NaOH Aluminum Solution, and (d) the Product Solution

The NaOH-aluminum solution showed only trace amounts of technetium and iodine. The activity from this solution was considered negligible in the recovery calculations. Because the dissolved LEU solution (listed as "Dissolver Solution" in Table 1) was heavily loaded with fission products and actinides, the results may not be quantitative due to the resulting interference in the gamma peaks. There is also some uncertainty in the solution volume because of evaporation. Gamma analysis of this solution calculated approximately $32 \mu \mathrm{Ci}$ of Mo-99, assuming a final volume of $700 \mathrm{~mL}$. The "Mo Separated Filter" contained approximately $1.9 \mu \mathrm{Ci}$ of Mo-99. To obtain this sample, the precipitate was dissolved in acid followed by the quantitative precipitation of Mo with $\alpha \mathrm{BO}$. This loss in product can be attributed to Mo-99 being trapped within the precipitate.

Gamma analysis of the product solution showed strong signals from technetium, molybdenum, iodine, and several xenon isotopes as a result of iodine decay. We assume the concentrations of Mo-99 in the product solution to be quantitative on account of the chemical treatment and hindered gamma interference. The Mo-99 recovery was calculated from the sum of the Mo-99 captured on the filter (loss) and the product solution, which results in over $92 \%$ recovery ( $\pm 1-\sigma$ notation from counting statistics). From Table 1 we can approximate that $30-50 \%$ of the iodine was recovered based on the 133 and 131 isotopes, though we had anticipated that more I-131 should be present. The U-237 tracer (induced by photon reactions 
TABLE 1 Gamma analysis Results of the Electrochemical Dissolver Process. These values have been decay-corrected to the time of irradiation.

\begin{tabular}{|c|c|c|c|c|}
\hline \multirow[b]{2}{*}{ Isotope } & \multicolumn{3}{|c|}{$\mu \mathrm{Ci}$} & \multirow[b]{2}{*}{$\begin{array}{c}\% \text { Mo } \\
\text { Recovered } \dagger\end{array}$} \\
\hline & $\begin{array}{l}\text { Dissolver } \\
\text { Solution* }\end{array}$ & $\begin{array}{c}\text { Mo Separated } \\
\text { Filter }\end{array}$ & $\begin{array}{l}\text { Product } \\
\text { Solution }\end{array}$ & \\
\hline Mo-99 & 32.1 & 1.9 & 25.6 & $92 \pm 3$ \\
\hline U-237 & 16.7 & & 0.7 & \\
\hline La-140 & 5.6 & & 0.7 & \\
\hline $\mathrm{Zr}-95$ & 1.4 & & 0.1 & \\
\hline Nb-95 & 0.2 & & ND & \\
\hline Nd-147 & 0.8 & & 0.1 & \\
\hline Np-239 & 10.2 & & 0.3 & \\
\hline Te-132 & 0.7 & & 0.1 & \\
\hline I-133 & 32.3 & & 11.1 & \\
\hline I-131 & 1.6 & & 0.9 & \\
\hline Ru-103 & 0.3 & & $<0.1$ & \\
\hline Rh-105 & 1.4 & & 0.1 & \\
\hline
\end{tabular}

* These values may not represent the true values on account of the uncertainty in solution volume and gamma-interference.

$\uparrow$ Calculated from the sum of the Mo Separated Filter and the Product Solution

$\mathrm{ND}=$ below detection limit or complications with the peak shape.

with U-238) confirms that over $95 \%$ of the uranium was removed with the precipitation step and the single in-line filter. This removal efficiency can be improved with additional filters and Mo purification.

To demonstrate the compatibility of this technology with back-end Mo purification procedures, an aliquot of the product solution was mixed with AG-MP-1 (BioRad) anion exchange resin. Gamma analysis of the product solution afterwards showed that technetium, molybdenum, and iodine were strongly retained on the resin. 


\section{CONCLUSION AND FUTURE ACTIVITIES}

A novel process to separate Mo-99 from irradiated LEU-foil targets has been described here. The technology is designed to electrochemically dissolve the LEU foil in a bicarbonate solution, which offers many advantages over acidic nitrate processes. The actinides and the majority of the fission products can be precipitated, with technetium, molybdenum, and iodine remaining in solution. The product solution can be fed directly to current Mo-purification

processes. This technology was tested with an irradiated LEU foil and demonstrated over $92 \%$ Mo-99 recovery, as well as appreciable separation from actinides and fission products. In the future, we would benefit from higher burnup experiments to gain a better understanding of the behavior of fission products and from electron microscopy of the uranium precipitate to better understand the precipitation step. 


\section{REFERENCES}

Gelis, A.V., G.F. Vandegrift, S.B. Aase, A.J. Bakel, J.R. Falkenberg, M.C. Regalbuto, and K.J. Quigley, 2003, “Argonne Progress in Developing a Target and Process for Mo-99 Production: Cooperation with CNEA," Proceedings of the International Meeting on Reduced Enrichment for Research and Test Reactors, Chicago, IL, October.

Gottardi, W., Iodine and Iodine Compounds in Disinfection, Sterilization, and Preservation, S.S. Block, Lea \& Febiger, Philadelphia, PA, USA (2000).

McLaren, J.A.,W.D. Cline, H.S. Clinton, J.J. Finley, J.H. Goode, and J.A. Westbrook, 1950, The Electrolytic Dissolution of Metallic Uranium, ORNL K-587, Oak Ridge National Laboratory.

Sunder, S., L.K. Strandlund, and D.W. Shoesmith, 1996, Anodic Dissolution of $\mathrm{UO}_{2}$ in Slightly Alkaline Sodium Perchlorate Solutions, AECL 1144, Atomic Energy of Canada Limited.

Vandegrift, G.F., A.V. Gelis, S.B. Aase, A.J. Bakel, E. Freiberg, Y Koma, and C. Conner, 2002a, "Argonne Progress in Developing a Target and Process for Converting CNEA Mo-99 Production to Low-Enriched Uranium," Proceedings of the International Meeting on Reduced Enrichment for Research and Test Reactors, San Carlos de Bariloche, Argentina,November.

Vandegrift, G.F., C. Conner, S. Aase, A. Bakel, D. Bowers, E. Freiberg, A. Gelis, K.J. Quigley, and J.L. Snelgrove, 2002b, "RERTR Progress in Mo-99 Production From LEU," Proceedings of the $6^{\text {th }}$ International Topical Meeting of Research Reactor Fuel Management (RRFM), Ghent, Belgium, March.

Wu, D., S. Landsberger, B. A. Bucholz, and G. F. Vandegrift, 1995, "Processing of LEU Targets for Mo-99 Production - Testing and Modification of the CINTICHEM Process," Proceedings of the International Meeting on Reduced Enrichment for Research and Test Reactors, Paris, France, September. 
This page intentionally left blank 



\section{Argonne}

\section{Chemical Sciences and Engineering Division}

Argonne National Laboratory

9700 South Cass Avenue, Bldg. 205

Argonne, IL 60439-4837

www.anl.gov

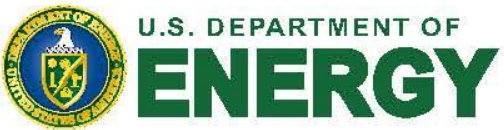

Argonne National Laboratory is a U.S. Department of Energy

laboratory managed by UChicago Argonne, LLC 